2014-07-03

From apprenticeship to higher

education: navigating the credential

landscape

\title{
Dismore, Harriet
}

http://hdl.handle.net/10026.1/8629

\author{
10.1080/13636820.2014.916737 \\ Journal of Vocational Education \&amp; Training \\ Informa UK Limited
}

All content in PEARL is protected by copyright law. Author manuscripts are made available in accordance with publisher policies. Please cite only the published version using the details provided on the item record or document. In the absence of an open licence (e.g. Creative Commons), permissions for further reuse of content should be sought from the publisher or author. 
From apprenticeship to higher education: navigating the credential landscape

Harriet Dismore, University of Southampton

Words: 7,842

Corresponding author:

Dr Harriet Dismore

Southampton Education School

University of Southampton

Building 32

Southampton

SO17 1BJ

Email: H.Dismore@soton.ac.uk 


\section{Abstract}

The credential landscape of vocational and higher education in the UK has expanded in recent years, alongside a rise in the number of students undertaking qualifications and a steady increase in tuition fees. The transition from an apprenticeship to higher education is one example of the progression from vocational to higher education. However, the ways in which this pathway is navigated according to the students who have followed this route, has received little attention. This paper focuses on the examples of four students in England who each progressed to higher education with different qualifications. Drawing on Archer's concept of reflexivity, the analysis revealed three important factors for negotiating transition. These were firstly the credential landscape itself, secondly how their employer perceived higher education credentials and thirdly how higher education institutions perceived vocational credentials. The findings illustrate how students confronted and overcame the various constraints and barriers in order to pursue higher education.

Keywords: apprenticeship; higher education; transition; employability 


\section{Introduction}

Over the last four decades it is reported that UK higher education has grown from around 600,000 students in the 1970 s to 2.5 million (Milburn 2012; HESA 2013). Higher education is the term adopted to encompass all accredited learning beyond level 3, so that it includes not only full-time bachelor degrees but other higher level qualifications such as Foundation degrees (level 5), NVQ levels 4 and 5, Higher National Diplomas (HNDs) / Higher National Certificates (HNCs) and recognised professional qualifications that are not awarded by higher education institutions. Despite hopes and expectations, it has been argued that this expansion has not led to widening participation (Ball 2003; Sutton Trust 2005). As Milburn (2012) emphasised in his report on social mobility, UK universities remain less open to people from lower and middle income groups in society than those in countries such as the US or Australia. Nor has it meant equality of job prospects. For example, graduates from disadvantaged backgrounds are found to do less well than their middle-class peers in earnings (Morrison 2012).

Vocational higher education programmes have also expanded, particularly with the arrival of the Foundation degree in 2001. Introduced in the UK (except Scotland), the rationale is for universities, colleges and leading employers in the field to design Foundation degree courses in partnership so that education is linked to intermediate-level occupations or the mid-skilled labour market. This means that although each Foundation degree is necessarily different in content, they place great emphasis upon employer involvement and work-based learning (Beaney 2006). Designed as a qualification in its own right attracting 240 credits (120 each at Levels 4 and 5), it can be undertaken full-time over two years or part-time over 
a longer period. It can also count towards a full Bachelor's degree with a further 12-15 months of full-time study.

Although a time of economic downturn in England, the UK Government announced in 2010 the intention to invest over 600 million pounds a year into apprenticeships (BIS 2010). This led to an increase of 520,600 people starting an apprenticeship in 2011/12 (BIS 2013). The term 'apprenticeship' now refers to a range of government-funded programmes including 'Foundation Apprenticeships' leading to level 2 qualifications, 'Advanced Apprenticeships' leading to level 3 qualifications and 'Higher Apprenticeships' at level 4 (Brockmann, Clarke and Winch 2010). Apprenticeships are frameworks designed by Sector Skills Councils rather than qualifications, but have to include a National Vocational Qualification (NVQ) (competency-based), a Technical Certificate (knowledge-based), functional skills (numeracy and literacy) and a module on employment rights and responsibilities (Skills Commission 2009). Despite these common components, there exist many different apprenticeship models within each sector subject area (Carter 2009).

Regardless of the structures and processes proliferating in order to encourage vocational learners such as apprentices to progress, there remains inequality and confusion:

At the system level, however, we have shown that despite the Government claim of 'parity of esteem', the traditional A-level route still opens up the best opportunities into those institutions with higher reputations. Those coming from a vocational background mostly end up in post-92 institutions with lower RAE and QAA results. 
The reasons for this are likely to be a combination of tracking within a stratified HE system and individual choice (Hoelscher 2008, 149).

This supports the view of Tomlinson (2013) that even though the vocational education landscape has evolved, there remains a hierarchy between vocational and academic pathways that perpetuates unequal outcomes. Furthermore, as Schuller and Watson (2009, 146) explained, 'the hyper-complexity of the UK's pattern of qualifications has led to all sorts of anxieties about equivalence, notably between so-called 'academic' and 'vocational' awards'. The desire for transparency has resulted in frameworks that map vocational and academic qualifications.

The Qualifications and Curriculum Framework (QCF) introduced in England, Northern Ireland and Wales in September 2010 reflected a general interest globally in developing qualification frameworks for a number of reasons. The aim of the QCF was to make the content of qualifications transparent and shift power (and responsibility) from the provider to the learner and employer, whilst also gaining central control. Table 1 shows levels 3 to 7 of the Framework for Higher Education Qualifications (FHEQ) and the Qualifications and Credit Framework (QCF) / National Qualifications Framework (NQF). The QCF maps on to the European Qualification Framework (EQF) introduced in 2008, to help comparison of national systems, frameworks and levels.

INSERT TABLE 1 HERE 
Despite a considerable increase in the number of people starting an apprenticeship in England (Leitch 2006, 97), only low numbers have progressed from non-academic routes to higher education (FDF/UVAC 2008; Skills Commission 2009; Milburn 2012). Smith and Joslin (2011) reported that $5.3 \%$ of apprentices in 2005/06 progressed to higher education immediately, although this figure rose to $13.1 \%$ after three years. One reason for this may be because the term 'apprenticeship' is not a qualification in its own right and therefore tracking students is difficult. Also, there is a paucity of information relating to part time students in higher education (Callender and Wilkinson 2013). Since many former apprentices study higher education part time, their experiences have received consequently little attention.

Those studies that have conducted research into progression from vocational to academic pathways have tended to do so from a transition to higher education perspective (e.g. Winter and Dismore 2010; Read, Archer and Leathwood 2003). There has more recently been an increasing number of studies into the decision making processes and choices of potential higher education students, especially in relation to the impact of fees (e.g. Callender and Jackson 2008; Wilkins, Shams and Huisman 2012). There is general recognition of a proliferation of information provided by universities to help students make choices about higher education (Briggs and Wilson 2007) but that the complexity of information is daunting and can deter prospective students from applying (Forsyth and Furlong 2003). A useful way of describing those moving between these so-called vocational and academic pathways is 'contextual incongruity' (Archer 2012), when foreground does not match background. For example, this might mean that personal values clash with the social context in which the person intends to inhabit. 
Little research has been carried out with apprentices who have progressed to higher education and those that have tend to focus on the need to map provision (Fuller and Unwin 2012) and examine progression patterns (Smith and Joslin 2011) rather than the lived experiences of those seeking to progress (Dismore 2013). Yet if apprentices are to progress to higher education then they need to know the requirements to do so. Research on apprenticeships has also largely neglected the way vocational qualifications at level 3 are valued and treated in contrast to academic qualifications (except Fuller et al. 2010). This prompted the decision to undertake this study, which questioned why apprentices progressed to higher education and what influenced their courses of action.

For a number of researchers, the value of higher education lies in the process of becoming (e.g. Hager and Hodkinson 2009; McArthur 2011; Dismore 2013). This view regards learning as a changing relational web in a process of ongoing change, inherently part of and shaped by its context, social and embodied (Hager and Hodkinson 2009). In other words, it encompasses learning through participation (Lave and Wenger 1991) and individual transformation (Mezirow 1991). This is important if, as Guile (2003) claims, the knowledge economy requires learners to develop a 'capacity to understand and anticipate change' (David and Foray 2002, 16) and to produce new knowledge. It also reflects a lifewide perception of lifelong learning as expressed by Billett $(2010,5)$, who warns that we should not ignore the importance of learning outside courses, because doing so promotes 'a form of learning support that lends itself to regulation and control'.

However, research that captures such a theory is limited, reflecting the complex relationship to structure and agency. Archer $(2003,2007,2012)$ addresses the interplay between structure 
and agency and importantly, seeks to avoid underplaying or overplaying human agency. To achieve this, Archer (1995) developed an approach of analytical dualism, recognising that agency and structure operate on different timescales. She argues that it is possible to unpick them analytically by investigating human reflexivity, which mediates between structure and agency.

Reflexivity is defined as 'the regular exercise of the mental ability, shared by all normal people, to consider themselves in relation to their (social) contexts and vice versa' (Archer 2012 , 1). People develop a personal identity that reflects what they care about in the world and in turn these interests and concerns can exercise personal powers to influence systems and practices. The ultimate goal of reflexivity is to realise a modus vivendi, 'a set of established practices that constitute a desirable way of life as defined by the subject in the light of his ultimate concerns' (Archer 2012, 223), both fallible and subject to revision.

Analytical dualism makes it possible to understand how structure and agency emerge, intertwine and redefine one another through the morphogenetic sequence. The morphogenetic sequence is based on the two basic propositions that structure pre-dates the actions that lead to transformation (morphogenesis) or reproduction (morphostasis) and that structural elaboration post-dates the action sequences that give rise to it (Archer 1995). The morphogenetic process can reveal educational practices such as the impact of external as well as internal systemic, cultural and social properties on social reproduction and change within a school and on individuals (Archer 1995). An example of this is the evolving and traditional working-class cultures in response to personal experiences and indirectly to policy interventions that encourage lifelong and work-related learning (Dyke et al. 2012). 
Reflecting the realist position, Archer (2011) distinguishes between structural and cultural systems (which have an objective existence) and the socio-cultural level where meaning is attributed. This is important when examining transitions to higher education whereby employment structures and qualification frameworks are regarded as structural systems influencing (and being influenced by) the socio-cultural practices performed by, for example, employers and higher education institutions.

The work of Archer (2003) led her to identify four modes of reflexivity that influence the way that agency is exercised: autonomous reflexives who base their actions principally on their own internal conversations; communicative reflexives who share their inner dialogues with others before deciding on a course of action; meta-reflexives who are concerned with effective action within society; and fractured reflexives whose deliberations can cause anxiety preventing purposeful courses of action. Indeed, the higher education environment is said to valorise autonomous reflexivity, particularly given the focus on students to be selfdirected and flexible (Clegg 2010). However, empirical data suggests that rather than fixed modes of reflexivity they are approaches that can be used in any given situation (Dyke et al 2012; Kahn, in press).

\section{Methodology}

To enable exploration of factors influencing transition via reflexivity, individual interviews were chosen to collect data. All interviews were semi-structured so as to provide an opportunity for the researcher to explore a number of areas of interest without closing down the introduction of themes considered important to the interviewee themselves. 
The total sample for this study consisted of nineteen individuals located in the south of England. They worked in three broad sectors: computer science, engineering and childcare and the majority worked in engineering (15). The institutions in which they were studying include two further education colleges, one pre-1992 university and four post-1992 universities. The majority of participants were in their 20s (17) and male (15). The sample was purposefully small to enable detailed investigation into their learning experiences.

For the purpose of this paper, four cases of former apprentices are drawn on to clearly illustrate how transition was experienced by individuals. The cases presented in Table 2 were selected to represent the credential pathways experienced by those progressing from an apprenticeship to higher education: Ray complemented his apprenticeship with a certificate of higher education before progressing to a Bachelor of Science degree (BSc) full time; Natalie completed national vocational qualifications (NVQ) levels 2 and 3 before embarking on a Foundation degree part time; Anna had completed ' $A$ ' levels before beginning her apprenticeship which enabled her to fast track progression to a Bachelor in Engineering degree (BEng); and Richard completed a business and technology education council qualification (BTEC) as part of his apprenticeship and two higher national certificates (HNC) qualifications prior to completing a Foundation degree. These represent the credential pathways experienced by the original sample of nineteen interviewees and, it is suggested, are likely to represent pathways experienced by other former apprentices who enter higher education.

INSERT TABLE 2 HERE 
Data gathering took place between August 2011 and April 2012. Each participant was interviewed in-depth for approximately one to two hours. Questions included 'how did you find out about the course', 'how and when did you make the decision to do the course', 'what concerns did you have (if any) prior to enrolment and what were the reasons you wanted to do the course?' Prior to data collection, ethical approval was obtained from the University Ethics Committee. All participants were assured that their information would remain anonymous to protect their identity. Interview participants were also provided with an information sheet and asked to provide their consent. This confirmed their understanding of the process, how the data would be used and their right to withdraw at any time without needing to justify their decision. All of the transcripts were returned to each participant for comments and/or amendments.

The interviews were fully transcribed and analysed using the NVivo 10 research software to capture how, 'the subjectivity powers of reflexivity mediate the role that objective structural or cultural powers play in influencing social action' (Archer 2007, 5). A theme that emerged from this analysis and reported here was the decision making to progress to higher education and more specifically, the perceived worth of credits.

\section{Findings}

The findings are presented in three sections. The first section introduces the four participants, their routes and the qualifications they had attained prior to progressing to higher education. Progression to higher education was often facilitated by additional qualifications in addition to the ones obtained as part of the apprenticeship such as a certificate in higher education gained specifically to access a BSc. The second section 
presents the perceived worth of higher education credentials for employment and the relative importance attributed to this worth. The third section shows how participants perceived vocational credentials for accessing higher education, including the responses of HEI staff. Overall, the findings demonstrate a range of structural, cultural and socio-cultural factors that provided a context for transition and had to be negotiated, particularly in the face of 'contextual incongruity'.

\section{Participants}

Case 1: Ray

At 25 years old, Ray had completed an apprenticeship in mechanical engineering and was in the second year of a BSc degree in mechanical engineering in motorsport full time at a pre$1992 \mathrm{HEI}$. Overall, Ray's decision to progress to higher education was influenced by his own aspiration as well as a number of structural and cultural factors. One of the reasons Ray gave for progressing to HE was that,

there's got to be something more than what I've seen these people I've been working with doing, standing around next to their toolbox for thirty years you know, talking about the same thing or slightly different things. And I just wanted something, I wanted to do something more.

As this shows, the employment structure and culture did not match his interests. Ray's concern was that he was capable of achieving more than his employment would allow him to demonstrate. This contextual incongruity prompted him to exercise his agency. However, several other incidents reportedly led to his decision to progress to higher education. Firstly, 
Ray's grandfather who had been an engineer died during his apprenticeship. Following this he asked to attend an exploring engineering course at a partner university, giving him his first experience of a university. The opportunity to attend this course represents an additional structural enablement. There he talked to someone whose aspiration it was to do a motorsport engineering course and as he said, 'then all of a sudden it become [sic] almost a goal of mine'. This highlights the importance of structures for enabling opportunities for social interaction, which in turn helped Ray to delineate and prioritise his concerns. Sometime later, Ray went on holiday to Thailand and returned inspired by the story of his girlfriend's father who had achieved success despite his relatively poor upbringing. On his return, he rang the university of his choice:

I said that I was an apprentice and was there any way of an apprentice getting into, with level 3 qualifications, into university? And she said that they'd previously had some people in the same situation go to [name] University and gain a certificate of higher education in physics and mathematics and then they can, they've actually accepted them [sic] people. So I took the name from her and I rang up [the college] and they said to come down for an interview to start that September.

As this explains, the decision to pursue higher education was influenced by a number of different factors and events, all contributing to an evaluation of the courses of action deemed feasible. However, the NVQ level 3 in mechanical engineering obtained by Ray was not deemed adequate for progressing to the BSc and he had to enrol on an evening course to pass the certificate of higher education at a local college. Indeed, as well as this the level 
of work demanded for this certificate acted as another potential barrier. Yet he sought to overcome this difficulty by drawing on the available resources:

I didn't have a clue to be honest, I just, it's never ever going to happen, I just don't know these things. But then I spoke to my brother who done his, who done ' $A$ ' Levels, didn't do too well but he knew more than I did. He showed us quickly like roughly what it meant. So then I sat down and I worked through the whole paper, went in, got $100 \%$ on both physics and maths in the paper ...

The reflexivity of Ray shows how his aspiration and a commitment to hard work were employed to mediate the different structural and cultural barriers he faced. Interestingly, it also demonstrates how these led to a reliance on the people around him in an engaging and affirmative way. This 'thought and talk' pattern is described by Archer (2007) as characteristic of communicative reflexives.

\section{Case 2: Natalie}

Natalie was 25 years old and had completed an apprenticeship in childcare and learning development. She had progressed to a further education college to undertake a Foundation degree in children and young people part time whilst working at a private nursery. Rather than 'staying put' and seeking a job to suit her level of study, Natalie was planning to progress with the sole purpose of working her way up within the employment structure. She was determined to be a manager in a children's centre and to do this she knew she had to reach a certain academic level: 
This is the one that I wanted to do, definitely, just because of what I want to become in years, a manager. And obviously you have to do a Level 4 to be a deputy manager...

This supports Evetts (2008) who claimed that jobs traditionally operated from relatively low skills thresholds now require additional education. However, the decision to progress for Natalie was characterised by more caution than that of Ray. This seemed to have stemmed from a particular expectation of university based on others' experiences. As the following extract illustrates, Natalie had little confidence that she was 'really smart', something she considered a prerequisite for university:

Just because I'd never sort of thought about going to university, and whenever you hear 'university', it's quite a big step and you feel, I mean friends and family members who have gone to university have always done really big things like law, journalism, and then you have someone doing a foundation degree and working with children, and they're like you're going to uni for that? And then it makes you feel like am I supposed to be going to uni for this? And you have all these expectations that you're supposed to be really smart to go to uni, and worries like that come into play.

In other words the higher education culture, as understood and communicated by Natalie's friends and family, was perceived to be intimidating. Whereas for some these concerns might have led to inaction, it is interesting that Natalie forged ahead with the transition. The evidence suggests that this was facilitated through social interaction within the 
classroom. Indeed she appreciated the small social setting of the Foundation degree class, learning with others employed in the same sector and particularly embraced the opportunity to mix with and learn from people already in the position of manager.

... we have such a wide range of people, and a wide age range as well, who have also gone through the same processes as you, and obviously their experience on how they've got there, how they're finding it, because a lot of the people in the group are managers, so it's always nice to hear their experiences through obviously working as managers but doing the course at the same time.

Like Ray, the 'thought and talk' pattern supported her by providing information and experience that would otherwise have eluded her. This example highlights the important role of the setting, as well as the social interaction it encouraged, for helping Natalie overcome the perceived incongruence between her vocational background and higher education.

However, unlike the case of Ray, Natalie's level 3 NVQ in advanced childcare and education was deemed adequate to enable progression to a Foundation degree. This meant that she did not have to complete a Certificate in Higher Education before enrolling, an additional potential barrier for someone with low confidence like Natalie. Nevertheless, this arguably highlights how the expansion of higher education has in turn elaborated the structure so that it can engage part-time, mature students such as Natalie. Furthermore, by developing her confidence Natalie herself is transformed, resulting in double morphogenesis. 
Case 3: Anna

Anna was 24 years old and completing a BEng at a post-1992 HEl part time. She had obtained ' $A$ ' levels in chemistry, biology, English literature and French. Unlike Ray or Natalie, Anna demonstrated 'under-developed reflexivity' (Archer 2012) by seeming to exercise her agency solely in relation to the present moment and current circumstances. In this way her progression seemed opportunist rather than strategic, as she described when asked what made her choose the apprenticeship route:

Basically indecision! I did my ' $A$ ' Levels and it was just two years of intense study really that I didn't really find I applied myself to as much as I should have done, so I didn't want to go to university because I figured I'd waste a couple of years more maybe. I took a year out and then I found the apprenticeship because it was, well it was work based basically, it was more catered to what I thought I wanted to do. And engineering's quite difficult to get into regardless, so I figured a work route might be a bit more advantageous!

Her lack of reflexivity may have been due in part to the fact that she had already obtained ' $A$ ' levels. She later commented on the relatively low level of risk attached to choosing an apprenticeship route when she knew that she could have gone to university:

There was a little bit of reassurance with me because I kind of did know that I could go to university, I could leave and go to university using my 'A' Levels, or I could progress through, but I didn't realise it would take quite as long as it would do if I had two levels of HNC. 
In this way, ' $A$ ' levels can enable transition rather than act as a barrier or constraint. However, it was also because she had ' $A$ ' levels that eventually she felt dissatisfied with her position. The company had set routes for those without ' $A$ ' levels which she did not feel suited her own circumstances:

I'd gotten to a point where I was like I don't want to do another two years of HNC because I'd basically be doing my ' $A$ ' Levels again. And Jo, my boss, was like 'well don't leave that's completely ridiculous, we'll support you through a degree, if you post forward your proposition, like with the uni that you want to go to, the degree you want to do then we'll have a look at it and I'm sure we'll happily support you'.

In other words, although Anna at first experienced more contextual continuity than the other participants between her academic background and higher education, she realised that her ' $A$ ' levels could be used more effectively to bypass the HNC that other apprentices were completing. Like Natalie, prompting this change also led to structural elaboration as the system was adapted to suit Anna's requirements.

\section{Case 4: Richard}

Richard was 39 years old working for a government organisation and studying part time for a BEng. Previously he had completed a BTEC national diploma as part of his apprenticeship in the Army. As soon as he could he left the Army and moved to Scotland where he completed two HNC qualifications. Then he moved to the south of England where he completed a Foundation degree at a post-1992 institution. When interviewed he was 
progressing from a Foundation degree to a BSc in electronic engineering at the same university.

Richard began his career as a soldier and quickly realised that he did not enjoy the physical aspects of military training but enjoyed learning:

I enjoyed the academic side, I struggled a bit at maths, I've always struggled, I've passed but you know ... I think within the Army system you're living with the same people in the block all the time, because you live with them, work with them all the time, there's a lot of rivalry, you know in good humour of course, but there's a lot of competition to finish top of the class and to beat each other at exams ...

The following quote demonstrates that he was quite autonomous in the way that he planned his future and that he had already decided to pursue further education when he left his employment.

I moved to Scotland. When you leave the Army you get a re-settlement grant, you get a lot of support with training and things like that, you can go and get work experience, and by that stage I'd already decided I wanted to go into further education. So I got a place at [name] College to do an HNC in what I thought was electronic engineering and the Army agreed to pay for that as my re-settlement.

In this way, the structural support provided by the Army was combined with a personal interest in finding a job working in 'Silicone Glen and all the big electronic companies there, 
which was another reason for doing the HNC'. However his concerns about finding a job were compounded by the fact that he had started a family and the risks involved in this were foremost in his mind: 'the possibility of losing your job focuses your mind a bit more and you know I had my first child when I was doing my HNC'. It was probably because, as he explained, he had to complete six years of an apprenticeship before being allowed to leave the Army, which led him to be cautious about committing to long courses:

So I was only committing myself to one year, I was going to get a qualification at the end if I passed, and it was a way to dip my toe back in without ... You know I wouldn't, if I had to commit to three years again, I'm not sure I would have enjoyed that.

Despite having the support of some structural enablements (funding) and his own motivation, emerging constraints were presenting themselves in relation to other personal circumstances such as his family and a reluctance to commit to years of study. His progression was shaped by these factors, which in turn dictated the mode of study (part time), time commitment to study and job role. In contrast to the other participants, it is not clear whether or not Richard would have been accepted onto the Foundation degree without his additional HNC qualifications. It is possible that, like Natalie, this would have been acceptable although the question of currency might have been raised given that the BTEC national certificate was awarded in 1992.

As these findings show, there was a complex interplay of structural and cultural factors that impacted on students seeking to exercise their agency, in addition to the different personal 
powers that students had in their possession. However, as the following sections show, the meaning attributed to the different credentials and pathways by employers and higher education institutions was also of concern.

\section{EMPLOYER RECOGNITION}

For many of the participants in this study, the decision to progress to higher education was made to improve their employment prospects and therefore, it was important that higher education was recognised by either current or future employers. In this way employer recognition emerged as an important socio-cultural factor that influenced participant perceptions of transition. Yet it was interesting to note the kinds of materials that were used to gauge recognition. For example, the main reason Ray looked to pursue higher education was that,

when you look at job adverts, they're not asking for people with National Certificates or National Diplomas, they want degrees or HNCs, HNDs you know, to get, up the pace you need better qualifications, you know, and you need the experience as well but ... It was just something I felt I needed to do if I wanted to get better jobs.

There was therefore a need for students to locate the correct information in order to allay any fears. This was certainly the case for Natalie who, when asked how she decided to progress to higher education, said:

But I kept umming and aahing, and I think that's because I didn't have enough information and didn't really know what was expected of me, and then I had other 
people saying oh it's going to be too much for you. So I think that once you've said to yourself, OK I'm going to have a little gap and then I'm going to go, you should just go straight for it, definitely.

This demonstrates that for a period of time, low confidence did prevent Natalie from progressing to higher education. Interestingly, she attributes this personal uncertainty at least partly to the information available to her from employers. In her words,

when you begin your level 3 it tells you you can do your level 4 which will you know be useful if you're deputy manager and you have to do it if you're a manager, blah, blah, blah. That's all you get told, there's nothing about a Foundation degree, nothing.

A greater need for advice and guidance among those progressing to higher education study from a vocational background has been called for by Ertl and colleagues (2010). As Natalie's progression was entirely motivated by the employment structure, the information provided by the sector was especially important and would justify her efforts to overcome her low confidence.

However, it is possible that an absence of information works in the favour of the employer and that these barriers are strategic rather than accidental. By not presenting clarity about this, the employer is not tying themselves to any guarantee or promise of recruitment. This may also have been the case for Anna who reported that she had not been made directly aware that progression was open to her. She explained that the opportunities to progress 
were 'an unspoken thing':

But they don't lay it out there and say you can have this confidence in what we'll do, because if you work hard we'll carry on to send you to uni, you know. And it's kind of, it's an unspoken thing mostly because your peers have gone on and done it, but when I joined the degree certainly it wasn't proposed by my employer, it was me...

Anna started to exercise her agency when she became dissatisfied with the HNC because it lacked challenge. When she approached her line manager with the concern, he was reported to say, 'well don't leave that's completely ridiculous, we'll support you through a degree'. She then presented the details of the course to their line manager for approval.

The example of Anna also highlights the importance of presenting information on higher education courses with employers in mind as well as students. The key position of the employer with responsibility for enabling progression to higher education is something discussed by Bills (2003). Bills argued that credentialism puts power in the hands of the employer rather than the individual and can be discriminatory as a result. This might happen in the context of recruiting, when for example more highly schooled applicants possess an array of social and interpersonal dispositions that employers might value. However, there remains a lack of research into how these forms of cultural capital are attractive to employers over specialised skills such as those needed in the technical industries.

The decision not to offer opportunities for progression can also protect employees from becoming over-qualified and experiencing what Allen and Van der Velden (2001) described 
as a mismatch. They undertook a study to examine the relation between educational mismatches and skill mismatches. They found that skill mismatches were a much better predictor of job satisfaction than educational mismatches. Indeed, as they concluded, 'adjustments in the labour market are strongly driven by the relation between job content and individual abilities, and less by the material and social rewards provided by work' (Allen and Van der Velden 2001, 450).

Another reason for a lack of information is simply because over time the landscape changes to such an extent that it is impossible to predict the qualifications required for jobs in the future. In this way the credential landscape itself acts as a structural barrier for employers as well as employees. How participants responded to this was interesting. For Natalie, although she was clear that she had to reach a certain level to secure the post she wanted, she was also mindful of how the requirements might change:

...so I thought why not just go the whole hog and do the Foundation degree? Because you can still do the Level 4 but I just thought, well in years to come Level 3 might be scrapped and Level 4 might be the minimum, so why not do it now while it's available.

Rather than allow the structural conditions to prevent her from progressing to higher education, she exercised her agency to project possible futures and planned accordingly. It is a strategy that demonstrates the process of weighing up possible outcomes, associated with rational choice theory (Abell, 1991) and is a characteristic of autonomous reflexivity (Archer, 2012). 
These findings suggest that how employers perceived higher education credentials was not always clear to prospective students and there were sometimes conflicting messages. The reasons for this are likely to be due to a number of factors at the structural and cultural levels. However, the data also shows that at the socio-cultural level, information is gathered from certain sources that could be more appropriately designed to help students make an informed choice.

\section{HEI RECOGNITION}

Like employer recognition, the response of HEls to credentials also influenced transition. This section alerts us to the confusion around the types of vocational credentials required in order to access higher education from an apprenticeship and the lack of consistency across and sometimes within HEls. It also demonstrates the impact on the agent in terms of anxiety caused when information was not readily available or when they received conflicting responses to requests.

For many the first interaction with a university was when using the website. Ray spoke about seeing the starting wages for mechanical engineers on the university website which enabled him to weigh up the costs and benefits of progression. As he explained, '...the jump for three years' worth of work, to either do it in work or to do it in university, I would have earned a lot more in pay, as I would have jumped up pay scales'. For Ray the information provided there about the labour market served to address his concern about whether a degree was worth the investment. This demonstration of rational choice theory (Abell, 
1991) serves to show the interaction between agency and structure at the point of decisionmaking.

However, the data showed the decision making process to be more complex and problematic than rational choice theory suggests. Arguably Ray was looking, regardless of potential bias, for evidence to support his intention to progress to higher education. In this way, it can be argued that Ray was actively selecting information to establish contextual continuity. It depended also on participants understanding the structure of the higher education landscape. Whilst Natalie referred to levels far more than qualifications, Ray found levels and the qualifications that equate to them very difficult to understand:

You've got people with BTECS, you've got people with all this kind of thing and they don't really, I don't think anyone knows at what stage you're at. It's quite a complicated system, I mean is it a level 3, is it GCSE, is it level 4, is it A level? Where am I? What's university, is that level 5, is that higher, is it further? What kind of education is this?

This supports the views of Fuller and Unwin (2012) that there remain serious questions about the currency of level 3 vocational qualifications as well as Carter (2009) who acknowledged the diverse and complex range of level 3 qualifications.

Indeed, how qualifications were compared appeared to be a barrier, particularly within the higher education institutions. All of the case study participants except Natalie made reference to the way that information was presented and the extent to which it was aimed 
at those who had completed ' $A$ ' levels or had undergone a 'conventional' route. Anna confirmed one institution's preference for ' $A$ ' level students when she remembered contacting her HEl: 'she said do you have ' $A$ ' levels, I said 'yes I did', she said 'well that would definitely help!" Interestingly, Richard considered it to be a conscious move to discourage those from alternative routes from progressing: 'Everything seems to be so focused in the conventional route that unconventional routes are almost discouraged from trying to get back into the mainstream I guess.' Ray too, when he was asked whether he would change anything about the information he received said, 'I didn't feel like the information that was available was for me really, you know?' David $(2010,11)$ made the point that higher education for many is the route most often compared to other routes.

Transitions into universities or higher education are challenging for many groups and is still a strong presupposition that the academic path is the 'royal road' into higher education against which all other paths are compared.

For all of the participants, it had taken personal courage and determination to approach HEls in the first place, in keeping with research into mature students pursuing vocational routes in to higher education (Reay 2001). The need for clarity around what constitutes the academic path for those with vocational backgrounds and qualifications emanates from the interviews presented here but is summed up particularly by Ray who argued that,

...if I knew the like the worth, or how to make my qualifications, my apprenticeship qualifications look worthwhile to someone in an admissions department, then that probably would have, that would have been more encouraging. 
Perhaps because Ray attended a pre-1992 institution he experienced more feelings of contextual incongruity at the point of entry. This was explained further when he reported how a member of staff has responded to him when he arrived at his institution to enrol:

...I come down and show them my transcripts, and then he turned round and said 'oh can I see your key skills in maths?' And I was standing there with a level 4 certificate for maths and he was asking for a level 2 certificate in maths and I was thinking I haven't even, I don't even think I've got it. And I was like I'm going to get turned away from the (laughs) I haven't even got in the door and I'm going to get turned away!

This illustrates clearly, as argued by Archer (2006), the potential for structural and sociocultural barriers to place the responsibility of access firmly on individuals, their aspirations and self-esteem. It also suggests a potential for this to lead to further inequality in the higher education system (morphogenesis). Importantly, it could also influence how students interacted with each other as well as with staff. When asked whether he talked to other students on the course about his route to higher education, Ray answered:

I didn't tell anyone really, except for some of the close people, especially not the lecturers. And then we had a drink with our lecturer at the end of the thing and he was from [pre-1992 HEI, he's done a PhD at [pre-1992 HEI] and I told him, oh yeah, I thought I'd done really well for someone that hasn't even got GCSEs. He almost spat 
his thing back into his pint! BOTH LAUGH. He was like, he just couldn't believe it! He was like what?! LAUGHS. You've got no GCSEs!

Not only does this reflect the influence of structure on socio-cultural practice but the impact on agency in terms of confidence and feelings of belonging at the university, as found by Christie and colleagues (2008). Together with the findings concerning employers' perceptions of qualifications, it seems that former apprentices have a great deal to navigate if they are to progress to higher education.

Gorard and Smith (2007) recognised there to be several key barriers to higher education, including the cost, time and travel, motivation and institutional barriers. In addition to these, this paper argues that the perceived worth of the vocational qualifications for the purpose of progressing to higher education are important socio-cultural factors that can influence employer support, access to the higher education institution and social interaction between and among students and staff. In a study by Reay and colleagues (2009), working class students underwent 'constant fashioning and re-fashioning of the self' in order to fit in to an elite university whilst retaining their working class values. This evidence suggests that the credentials themselves can be an important aspect of this process, permeating structures and agency. It stresses again the particular conceptualisation of achievements in education and how this manifests itself in educational market hierarchies (Tomlinson 2013).

\section{CONCLUSION}


Reflexivity operates amid a complex interplay between structures and agency. Examining how these inner conversations led to progression to higher education brought to bear particular mechanisms, barriers and contexts around which participants mediated. The strength of this approach was that it took as its starting point the potential powers of agency and structure to lead to action and in this case, progression. The cases presented in this paper represent four pathways involving different qualifications to progress to higher education at level 4. The data illustrates the lived experiences of students who navigate the credential landscape in order to successfully complete these transitions.

Despite the introduction of the QCF in 2010, the credential landscape remains problematic. As Howieson and colleagues (2013) reported following a study of credit transfer in Scotland, students need initiative, knowledge and resources if they are to take advantage of the opportunities available for progression. This study, focusing on the very people who progressed in England, revealed the extent to which there remain perceptions of inequality and no 'parity of esteem' (Hoelsher 2008) with academic routes continuing to be regarded as the 'Royal Road' (David 2010, 11).

As it has been stressed by Fuller and Unwin $(2012,23)$, 'in order for qualifications to have high exchange value in relation to entrance to $\mathrm{HE}$, their worth as appropriate measures for making selection decisions needs to be recognised by the HE sector.' This is not only important for widening participation and social mobility, but the concept of fair access. However, it is perhaps a reflection of the relative infancy of the QCF that staff at institutions cannot yet identify certain level 3 qualifications. Yet the findings illustrate the effects confusion can have even on those who do complete transitions to higher education. 
Whilst this study was necessarily aimed at participants for whom progression had already been made possible, there were several factors shown to influence perceptions of transition for those moving from vocational to higher education. It was clear that for those who remained in employment, substantial power remained with the employer to support and enable, both financially and practically, progression to higher education. It was therefore important to students that employers understood the value or worth of the credentials. Indeed, it was interesting to note that it could sometimes be the responsibility of the student to seek information about their preferred course and propose progression in return for remaining with the employer. If higher education is to attract part time and mature students in future, information must be produced with employers in mind as well as students. In this way, the socio-cultural practices that operate are just as important as the structural and cultural systems themselves.

Critically, this research emphasises the personal powers of agents in negotiating the transition to higher education. Indeed, the analytical dualism approach helped to identify the personal powers at different stages of transition and how these were used to address barriers and constraints at different levels of social organisation. Developing an understanding of this is needed if we are to develop appropriate and effective support mechanisms for students wishing to pursue higher education from a vocational background.

Reflecting the findings of Dyke and colleagues (2012), participants in this study appeared to use reflexive approaches in certain circumstances rather than as dominant modes (Archer 2003). Moreover, it seems possible that flexible reflexive approaches rather than fixed 
modes are more likely to successfully negotiate ongoing transformation of systems and practices (morphogenesis) and of agency itself (double morphogenesis).

Undertaking this study emphasised the difficulties of tracking advanced apprentices who have progressed to higher education. Indeed this meant that the final sample contained mostly engineering students rather than a sample representative of sectors. As UKCES reported in 2010, there is a lack of data and monitoring arrangements to track the progression of those pursuing applied and vocational learning beyond level 3. More robust and comprehensive data would certainly enable more regular and detailed research to be carried out into the pathways of former apprentices and also the extent to which the perceived worth of credentials for higher education might actually be deterring progression.

\section{Acknowledgements}

This research was carried out as part of the Society for Research into Higher Education (SRHE) Newer Researcher's Award, with support from the West London Lifelong Network (WLLLN). I am also grateful to all of the participants who gave their time and consent to be interviewed. Special thanks go to Dr Jamie Mackay for his support, Dr Michaela Brockmann for her comments on an earlier draft and the two anonymous reviews. 


\section{References}

Abell, P. (1991) Rational Choice Theory. Aldershot: Brockfield.

Allen, J. and Van der Velden, R. (2001) Educational mismatches versus skill mismatches:

Effects on wages, job satisfaction, and on-the-job search. Oxford Economic Papers 3, pp. $434-52$.

Archer, L. (2006) ‘Round Pegs into Square Holes? Critical issues for the widening participation agenda' in D. Jary and R. Jones (eds) Perspectives and Practice in Widening Participation in the Social Sciences, Birmingham: C-SAP.

Archer, M. (2012) The Reflexive Imperative in Late Modernity. Cambridge: Cambridge University Press.

Archer, M. (2011) Morphogenesis: realism's explanatory framework. In A. Maccarini, E. Morandi and R. Prandini (eds) Sociological Realism. London: Routledge, pp.59-94.

Archer, M. (2010) (Ed.) Conversations about Reflexivity. Abingdon: Routledge.

Archer, M. (2007) Making Our Way Through the World: human reflexivity and social mobility. Cambridge: Cambridge University Press.

Archer, M. (2003) Structure, Agency and the Internal Conversation. Cambridge: Cambridge University Press.

Archer, M. (1995) Realist Social Theory: the morphogenetic approach. Cambridge: Cambridge University Press.

Ball, S. (2003) Class Strategies and the Education Market: the middle classes and social advantage. London: Routledge.

Beaney, P. (Ed) (2006) Researching foundation degrees: Linking research and practice. London: FDF. 
Billett, S. (2010) The perils of confusing lifelong learning with lifelong education, International Journal of Lifelong Education, 29 (4), pp. 401-413.

Bills, D. (2003) Credentials, signals, screens and jobs: explaining the relationship between schooling and job assignment. Review of Educational Research, 74 (4), pp. 441-469.

Briggs, S. and Wilson, A. (2007) Which university? A study of the influence of cost and information factors on Scottish undergraduate choice, Journal of Higher Education Policy and Management, 29 (1), pp. 57-72.

Brockmann, M., Clarke, M. and Winch, C. (2010) The Apprenticeship Framework in England: a new beginning or a continuing sham? Journal of Education and Work 23 (2), pp. 111-127.

Business, Innovation and Skills (BIS) (2010) Skills for Sustainable Growth http://www.bis.gov.uk/assets/BISCore/further-education-skills/docs/S/10-1274skills-for-sustainable-growth-strategy.pdf. Accessed 30 ${ }^{\text {th }}$ May 2013.

Business, Innovation and Skills (BIS) (2013) Apprenticeship Statistics. Parliament Briefing Paper SN/EP/6113. www.parliament.uk/briefing-papers/SN06113.pdf. Accessed $30^{\text {th }}$ May 2013.

Callender, C. and Wilkinson, D. (2013) Futuretrack: part-time higher education students: the impact of part-time learning two years after graduation. A report to the Higher Education Careers Services Unit (HECSU). London: Birkbeck University/National Institute of Economic and Social Research.

Callender, C. and Jackson, J. (2008) Does the fear of debt constrain choice of university and subject of study? Studies in Higher Education, 33 (4), pp. 405-429.

Carter, P. (2009) Progression from Vocational and Applied Learning to Higher Education in England. Bolton: UVAC. 
Christie, H., Tett, L. Cree, V. Hounsell, J. and McCune, V. (2008) ‘A real rollercoaster of confidence and emotions': learning to be a university student. Studies in Higher Education 33 (5), pp. 567-81.

David, M. (Ed) (2010) Improving Learning by Widening Participation in Higher Education. London: Routledge.

David, P. and Foray, D. (2002) Economic fundamentals of the knowledge society, International Social Science Journal, 171, pp. 149-167.

Dismore, H. (2013) Experiencing the transition from an apprenticeship to higher education. Journal of Education and Work, DOI:10.1080/13639080.2013.802831.

Dyke, M., Johnston, B. and Fuller, A. (2012) Approaches to reflexivity: navigating educational and career pathways. British Journal of Sociology of Education, 33 (6), pp. 831-848.

Ertl, H., Hayward, G. and Hölscher, M. (2010) Learners' transition from vocational education and training to higher education. In M. David (ed) Improving Learning by Widening Participation in Higher Education. London: Routledge, pp. 75-88.

Evetts, J. (2008) Introduction - Professional Work in Europe: concepts, theories and methodologies, European Societies 10 (4), pp. 525-544.

Forsyth, A., and Furlong, A. (2003) Losing out? Socioeconomic disadvantage and experience in further and higher education. Bristol: Policy Press/Joseph Rowntree Foundation.

Foundation Degree Forward (FDF)/University Vocational Awards Council (UVAC) (2008) Features of Apprenticeship: Programmes that Support Progression to Higher Education. Summary of a project carried out by UVAC on behalf of FDF.

Fuller, A. and Unwin, L. (2012) Banging on the Door of the University: the complexities of progression from apprenticeship and other vocational programmes in England. Monograph No. 14. Cardiff: SKOPE. 
Fuller, A., Turbin, J. and Wintrup, J. (2010) Finding their way? Advanced apprenticeship as a route to HE. Southampton: University of Southampton.

Gorard, S. and Smith, E. (2007) Do Barriers get in the Way? A review of the determinants of post-16 participation. Research in Post-Compulsory Education.12 (2), pp. 141-158.

Guile, D. (2003) From 'Credentialism' to the 'Practice of Learning': reconceptualising learning for the knowledge economy. Policy Futures in Education 1(1), pp. 83-105.

Hager, P. and Hodkinson, P. (2009) Moving Beyond the Transfer of Learning. British Educational Research Journal 35 (4): pp. 619-638.

Higher Education Statistics Agency (HESA) (2013) Headline Statistics, http://www.hesa.ac.uk/. Accessed 30 ${ }^{\text {th }}$ May 2013.

Hoelscher, M., Hayward, G., Ertl, H. and Dunbar-Goddet, H. (2008) The transition from vocational education and training to higher education: a successful pathway? Research Papers in Education, 23 (2), pp. 139-151.

Howieson, C. and Raffe, D. (2013) The paradox of Scotland: limited credit transfer in a credit-based lifelong learning system. Oxford Review of Education, 39(3), 366-384.

Kahn, P. (in press) Theorising Student Engagement in Higher Education. British Educational Research Journal.

Lave, J. and Wenger, E. (1991) Situated Learning: legitimate peripheral participation. Cambridge: Cambridge University Press.

Leitch, S. (2006) Leitch review of skills: Prosperity for all in the global economy - World class skills (Final Report). Norwich: HMSO.

McArthur, J. (2011) Reconsidering the social and economic purposes of higher education, Higher Education Research \& Development, 30 (6), pp.737-749. 
Mezirow, J. (1991) Transformative Dimensions of Adult Learning. San Fransisco, CA: Jossey-Bass.

Milburn, A. (2012) University Challenge: how higher education can advance social mobility. A progress report by The Independent Reviewer on Social Mobility and Child Poverty. London: The Cabinet Office.

Morrison, A. (2012) 'You have to be well spoken': students' views on employability within the graduate labour market, Journal of Education and Work, iFirst.

Read, B., Archer, L. and Leathwood, C. (2003) Challenging cultures? Student conceptions of 'belonging' and 'isolation' at a post-1992 university. Studies in Higher Education 28 (3), pp. 261-77.

Reay, D., Crozier, G. and Clayton, J. (2009) Strangers in Paradise? Working-class students in elite universities. Sociology 43 (6), pp. 1103-1121.

Reay, D. (2001) Choices of degree or degrees of choice? Class, 'race' and the higher education choice process. Sociology, 35, (4), pp. 855-874.

Schuller, T. and Watson, D. (2009) Learning Through Life: inquiry into the future for lifelong learning. Leicester: NIACE.

Skills Commission (2009) Progression through Apprenticeships. London: Policy Connect.

Smith, S. and Joslin, H. (2011) Apprentice Progression Tracking Research Project Report. Longitudinal tracking of advanced level apprentice cohorts progressing into higher education 2005-06 to 2009-10. Centre for Work-Based Learning: University of Greenwich.

Sutton Trust (2005) State School Admissions to our Leading Universities. An update to 'the missing 3000'. London: Sutton Trust.

Tomlinson, M. (2013) Education, Work and Identity. London: Bloomsbury. 
UK Commission for Employment and Skills (UKCES) (2010) Progression from Vocational and Applied Learning to Higher Education across the UK. London: UKCES.

Wilkins, S., Shams, F. and Huisman, J. (2012) The decision making and changing behavioural dynamics of potential higher education students: the impacts of increasing tuition fees in England, Educational Studies, 39 (2), pp. 125-141.

Winter, J. and Dismore, H. (2010) Investigating the experiences of foundation degree students progressing to an honours degree: an integrated approach. Journal of Further and Higher Education 34 (2), pp. 247-264. 